\title{
Hemoconcentration in ex vivo lung perfusion: A case report of a novel technique used in clinical lung transplantation
}

\author{
Andreas Wallinder, MD, ${ }^{\mathrm{a}, \mathrm{b}}$ Christoffer Hansson, MSc, ${ }^{\mathrm{c}}$ and Göran Dellgren, MD, PhD, ${ }^{\mathrm{a}, \mathrm{b}, \mathrm{d}}$ Gothenburg, \\ Sweden
}

Reconditioning of initially rejected donor lungs during ex vivo lung perfusion (EVLP) may increase the number of patients treated with a lung transplantation. ${ }^{1-3}$ Multiorgan donors often suffer from circulatory instability and therefore may be treated with massive crystalloid fluid infusions, which can result in pulmonary edema. EVLP of the donor lungs with a hyperoncotic perfusate theoretically can decrease the lung water content by absorbing alveolar and interstitial edema. ${ }^{4}$ The oncotic

From the Departments of Cardiothoracic Surgery, ${ }^{\mathrm{a}}$ Cardiothoracic Anesthesia and Intensive Care, ${ }^{\mathrm{c}}$ Transplant Institute, ${ }^{\mathrm{d}}$ Sahlgrenska University Hospital, Gothenburg; and Department of Molecular and Clinical Medicine, ${ }^{\mathrm{b}}$ Institute of Medicine, Sahlgrenska Academy, University of Gothenburg, Gothenburg, Sweden.

Disclosures: Authors have nothing to disclose with regard to commercial support.

Received for publication Oct 20, 2012; revisions received Feb 7, 2013; accepted for publication March 4, 2013; available ahead of print April 5, 2013.

Address for reprints: Göran Dellgren, MD, PhD, Transplant Institute and Department of Cardiothoracic Surgery, Sahlgrenska University Hospital, University of Gothen-

burg, SE-41345, Gothenburg, Sweden (E-mail: goran.dellgren@vgregion.se).

J Thorac Cardiovasc Surg 2013;145:e76-7

$0022-5223 / \$ 36.00$

Copyright (c) 2013 by The American Association for Thoracic Surgery

http://dx.doi.org/10.1016/j.jtcvs.2013.03.001 pressure of the perfusate, however, will decrease during perfusion as edema is absorbed. Eventually, the oncotic pressure in the perfusate may equal the oncotic pressure in the interstitial space and, at that time, the perfusat has lost its absorbing capacity. It has been suggested that the perfusate should be replaced intermittently with new solution, ${ }^{5}$ but instead we used hemoconcentration of the ex vivo lung perfusate to preserve the high oncotic pressure.

\section{MATERIALS AND METHODS}

Perfusion (Vivoline LS1; Vivoline Medical, Lund, Sweden) of an initially rejected donor lung was performed with Steen solution (XVIVO perfusion, Gothenburg, Sweden) mixed with red blood cells to a hematocrit of $10 \%$ to $15 \%$. A filter for hemoconcentration (Hemocor HPH 400; Medivators, Minneapolis, Minn) was connected to the EVLP tubing as a shunt after the roller pump (Figure 1, A). Hemoconcentration was performed intermittently during the EVLP procedure. The lungs were otherwise treated according to our regular protocol for EVLP. ${ }^{2}$

\section{RESULTS}

One pair of donor lungs initially rejected for transplantation because of an infiltrate on chest radiograph and inferior arterial oxygen tension $\left(\mathrm{PaO}_{2}\right)$ /inspired oxygen fraction

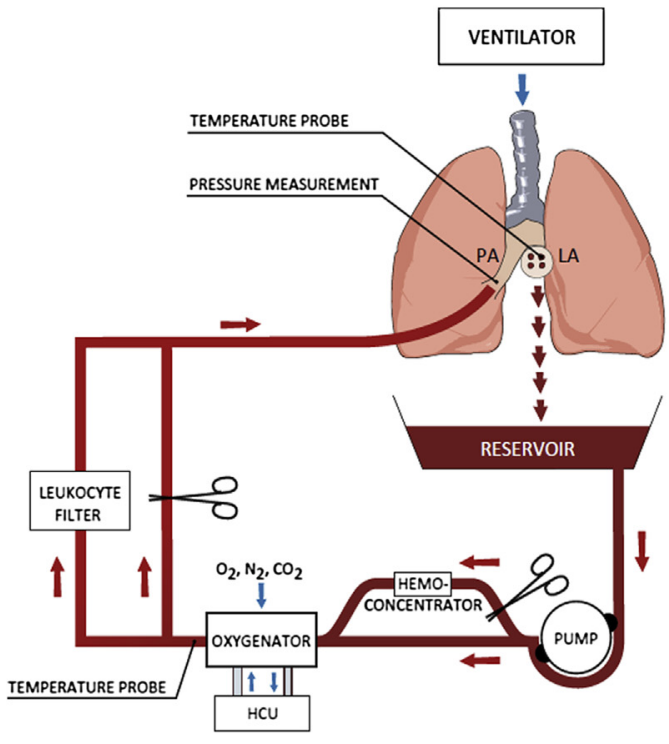

A

FIGURE 1. A, Schematic of the EVLP unit. The blood enters the open reservoir via the remnant of the left atrium $(L A)$. Samples for blood gas analyses are drawn from the pulmonary vein outflow and from a port after the oxygenator, where drugs also can be administered. The clamp on the hemofilter circuit allows for intermittent hemoconcentration. Pulmonary artery $(P A)$. B, EVLP data with volume of ultrafiltrate, pulmonary vascular resistance, osmolality, and oncotic pressure of the perfusate. $H C U$, Heater-cooler unit; $P V R$, pulmonary vascular resistance; $E V L P$, ex vivo lung perfusion. 
TABLE 1. EVLP data

\begin{tabular}{|c|c|c|c|c|c|c|c|c|}
\hline Time, min & 0 & 30 & 60 & 90 & 120 & 150 & 180 & 210 \\
\hline Hemofiltration, mL & 0 & 50 & 350 & 350 & 350 & 350 & 550 & 550 \\
\hline Temperature, ${ }^{\circ} \mathrm{C}$ & - & 17.4 & 35.0 & 36.5 & 36.5 & 36.5 & 36.5 & 31 \\
\hline Pulmonary artery flow, $\mathrm{L} / \mathrm{min}$ & 0 & 3.4 & 4.4 & 4.4 & 4.4 & 4.4 & 4.4 & 4.0 \\
\hline PVR, dyn $\cdot \mathrm{s} \cdot \mathrm{cm}^{-5}$ & 0 & 350 & 300 & 310 & 274 & 310 & 330 & 300 \\
\hline Oncotic pressure in perfusate, $\mathrm{mm} \mathrm{Hg}$ & 32 & 30.4 & 37.8 & 35.9 & 37.8 & 37.9 & 42.4 & 43.4 \\
\hline Osmolality, mOsm $/ \mathrm{kg}$ & N/A & 333 & 336 & 363 & 360 & 357 & 359 & 374 \\
\hline
\end{tabular}

$N / A$, Not applicable or not available; $P V R$, pulmonary vascular resistance.

$\left(\mathrm{FIO}_{2}\right)(10 \mathrm{kPa})$ was subjected to ex vivo reconditioning. The lungs were heavy with fluid and weighed $1150 \mathrm{~g}$ before being connected to the EVLP unit. EVLP was performed according to our regular protocol with reconditioning followed by functional evaluation. During perfusion the shunt to the hemofilter was opened intermittently and 550 $\mathrm{mL}$ of fluid was dialyzed from the perfusate. Oncotic pressure, osmolality, and pulmonary vascular resistance were recorded (Table 1). The donor lungs improved their oxygenation capacity to a $\mathrm{PaO}_{2} / \mathrm{FiO}_{2}$ of $53.7 \mathrm{kPa}$ at the end of the EVLP. During evaluation, hemodynamic (flow, pulmonary vascular resistance, pressure) parameters were stable (Figure 1,B). The hematocrit level increased from $10.8 \%$ to $11.4 \%$. A weight loss of $200 \mathrm{~g}$ was registered. The lungs were deemed suitable for transplantation and a patient from the regular waiting list underwent a double lung transplantation. The recipient was extubated after 20 hours and the $\mathrm{PaO}_{2}$ was $17.4 \mathrm{kPa}$ at 4 liters of oxygen on postoperative day 1 . Primary graft dysfunction was grade 0 at both 24 and 72 hours. The patient was discharged from the hospital on postoperative day 26 and is still doing well. The patient completed the 9-month follow-up evaluation and has had stable lung function parameters on spirometry during the entire postoperative period.

\section{CONCLUSIONS}

The hyperoncotic properties of the EVLP perfusate theoretically will decrease the lung water content. Despite this, we previously observed increased lung weight after EVLP in a number of cases. ${ }^{2}$ Replacement of the expensive hyperoncotic solution has been suggested but the effect of this maneuver seems unpredictable and no measurements of the oncotic effect have been published. ${ }^{5}$ When a hemofilter is included in the EVLP circuit the oncotic pressure can be maintained or increased during EVLP, but as shown in Figure $1, B$, the effect of the hemoconcentration procedure is delayed and unpredictable. Therefore, dialysis must be performed cautiously with continuous evaluation of EVLP parameters and ideally adjusted after intermittent sampling of the oncotic pressure. It is not possible to determine how much the improvement in lung fuction during EVLP depended on the hemoconcentration. However, when compared with edematous lungs previously evaluated, which in some cases gained weigh during EVLP, the weight loss of the lungs in this case might be an indicator of reduced lung edema.

As global demand for donor lungs increases and the number of multiorgan donors remains constant, everything must be done to increase the yield of lungs used. Novel approaches and the development of perfusion techniques are needed to optimize EVLP further. Hemoconcentration during EVLP is a promising method that we will continue to evaluate, especially in very edematous lungs, which may require EVLP with longer duration.

\section{References}

1. Aigner C, Slama A, Hotzenecker K, Scheed A, Urbanek B, Schmid W, et al Clinical ex vivo lung perfusion-pushing the limits. Am J Transplant. 2012;12: 1839-47.

2. Wallinder A, Ricksten SE, Hansson C, Riise GC, Silverborn M, Liden H, et al Transplantation of initially rejected donor lungs after ex vivo lung perfusion. J Thorac Cardiovasc Surg. 2012;144:1222-8.

3. Cypel M, Yeung JC, Machuca T, Chen M, Singer LG, Yasufuku K, et al. Experience with the first 50 ex vivo lung perfusions in clinical transplantation. $J$ Thorac Cardiovasc Surg. 2012;144:1200-6.

4. Steen S, Ingemansson R, Eriksson L, Pierre L, Algotsson L, Wierup P, et al. First human transplantation of a nonacceptable donor lung after reconditioning ex vivo. Ann Thorac Surg. 2007;83:2191-4.

5. Cypel M, Yeung JC, Hirayama S, Rubacha M, Fischer S, Anraku M, et al. Technique for prolonged normothermic ex vivo lung perfusion. J Heart Lung Transplant. 2008;27:1319-25. 